\title{
Prolonged exposure to GH impairs insulin signaling in the heart
}

\author{
J G Miquet, J F Giani, C S Martinez, M C Muñoz, L González, A I Sotelo, R K Boparai', \\ M M Masternak ${ }^{1,2}$, A Bartke ${ }^{1}$, F P Dominici and D Turyn
}

\author{
Departamento de Química Biológica, Facultad de Farmacia y Bioquímica, Instituto de Química y Fisicoquímica Biológicas (UBA-CONICET), Universidad de Buenos Aires, \\ Junín 956 (1113) Buenos Aires, Argentina \\ ${ }^{1}$ Geriatrics Research, Departments of Internal Medicine and Physiology, School of Medicine, Southern Illinois University, Springfield, Illinois 62794, USA \\ ${ }^{2}$ Institute of Human Genetics, Polish Academy of Sciences, 60-479 Poznan, Poland
}

(Correspondence should be addressed to J G Miquet; Email: jmiquet@ qb.ffyb.uba.ar)

\begin{abstract}
Acromegaly is associated with cardiac hypertrophy, which is believed to be a direct consequence of chronically elevated $\mathrm{GH}$ and IGF1. Given that insulin is important for cardiac growth and function, and considering that GH excess induces hyperinsulinemia, insulin resistance, and cardiac alterations, it is of interest to study insulin sensitivity in this tissue under chronic conditions of elevated GH. Transgenic mice overexpressing GH present cardiomegaly and perivascular and interstitial fibrosis in the heart. Mice received an insulin injection, the heart was removed after 2 min, and immunoblotting assays of tissue extracts were performed to evaluate the activation and abundance of insulin-signaling mediators. Insulininduced tyrosine phosphorylation of the insulin receptor (IR) was conserved in transgenic mice, but the phosphorylation of IR substrate 1 (IRS1), its association with the regulatory subunit of the phosphatidylinositol 3-kinase (PI3K), and the phosphorylation of AKT were decreased. In addition, total content of the glucose transporter GLUT4 was reduced in transgenic mice. Insulin failed to induce the phosphorylation of the mammalian target of rapamycin (mTOR). However, transgenic mice displayed increased basal activation of the IR/IRS1/PI3K/AKT/mTOR and p38 signaling pathways along with higher serine phosphorylation of IRS1, which is recognized as an inhibitory modification. We conclude that $\mathrm{GH}$-overexpressing mice exhibit basal activation of insulin signaling but decreased sensitivity to acute insulin stimulation at several signaling steps downstream of the IR in the heart. These alterations may be associated with the cardiac pathology observed in these animals.
\end{abstract}

Journal of Molecular Endocrinology (2011) 47, 167-177

\section{Introduction}

GH and its principal mediator, insulin-like growth factor 1 (IGF1), play an important role in cardiac development and in the maintenance of the structure and functionality of the heart (Colao 2008, DeBosch \& Muslin 2008). As cardiac myocytes express receptors for GH as well as for IGF1, GH may act in the heart directly or through the induction of local or systemic IGF1. The cardiac expression of IGF1 and of receptors for GH and IGF1 is influenced by hemodynamic changes, and both hormones are believed to exert stimulatory effects on myocardial contractility (Volterrani et al. 2000).

Both GH deficiency and excess are important risk factors for cardiovascular disease. In acromegalic patients, chronic GH and IGF1 overproduction leads to the development of biventricular concentric cardiac hypertrophy, characterized by myocardial hypertrophy with interstitial fibrosis and lymphomononuclear infiltration. This cardiac pathology is associated with diastolic dysfunction and, if hormone overload is not controlled, it may progress to systolic dysfunction and heart failure (Saccà et al. 2003, Climent et al. 2007, Colao 2008). Although acromegaly is frequently associated with hypertension, diabetes, and dyslipidemia, which are important risk factors for cardiovascular disease, the excess of GH and IGF1 per se is believed to be a major contributor to the specific cardiomyopathy observed in acromegalic patients (Ciulla et al. 1999, Saccà et al. 2003).

The main physiological role of insulin in the heart is the regulation of substrate utilization; however, insulin signaling influences several processes within the heart, such as cardiomyocyte growth, contractility, and apoptosis. In addition, insulin acts as a vasodilator in the coronary vasculature, therefore augmenting myocardial perfusion, and participates in the coupling of metabolic and hemodynamic homeostasis in cardiac tissue (Belke et al. 2002, Muniyappa et al. 2007, Bertrand et al. 2008, DeBosch \& Muslin 2008). Insulin exerts its cellular effects by binding to its membrane receptor (IR), which leads to the autophosphorylation of the 
receptor on several tyrosine residues. Once activated, IR binds and phosphorylates downstream mediators, including insulin receptor substrates (IRS) and Shc, activating two main signaling cascades: the phosphatidylinositol 3-kinase (PI3K)/AKT pathway and the mitogen-activated protein kinases (MAPK) pathway respectively (Dominici et al. 2005, Muniyappa et al. 2007, Bertrand et al. 2008, DeBosch \& Muslin 2008, Xu \& Messina 2009). Several Ser/Thr kinases activated by insulin, including mammalian target of rapamycin (mTOR) and the MAPKs Erk1/2, may phosphorylate IRS1 on specific serine residues inhibiting its functions, therefore acting as part of a negative feedback mechanism induced by insulin to terminate its action (Gual et al. 2003). Persistent stimulation of PI3K/AKT and/or MAPK pathways has been implicated in myocardial hypertrophy (Proud 2004, Bertrand et al. 2008). These signaling pathways are also activated by several growth factors, including IGF1 and GH (Dominici et al. 2005, Xu \& Messina 2009).

Chronically, GH actions oppose insulin effects. Acromegalic patients are hyperinsulinemic and insulin resistant, and about half of these patients develop diabetes mellitus (Møller \& Jørgensen 2009). The antiinsulin effects observed on prolonged exposure to GH are believed to be a consequence, at least in part, of the ability of $\mathrm{GH}$ to interfere with insulin signaling (Dominici et al. 2005, Xu \& Messina 2009). An adequate sensitivity of the myocardium to insulin is essential to maintain normal cardiovascular function (Yue et al. 2005, Muniyappa et al. 2007). Mice overexpressing GH have been extensively used as a model to study the effects of GH excess on the heart. These animals present cardiomegaly and develop concentric cardiac hypertrophy and alterations in cardiac functionality that may progress to heart failure, similar to that observed in acromegalic patients (Bollano et al. 2000, Colligan et al. 2002, Izzard et al. 2009). Considering the importance of insulin action on cardiac function, and taking into account that persistent elevated levels of $\mathrm{GH}$ are associated with hyperinsulinemia, insulin resistance, and anatomical and functional alterations in the heart, it is important to evaluate the sensitivity of the heart to insulin in conditions of chronic $\mathrm{GH}$ excess, as occurs in acromegaly.

Previous studies from our group have demonstrated impaired insulin signaling in the liver and skeletal muscle of GH transgenic mice in response to acute insulin stimulation (Dominici et al. 1999a,b). We hypothesize that chronic GH excess is associated with insulin resistance in the heart, which may be due to impaired insulin signaling in cardiac tissue. Therefore, the objective of this study was to establish the effect that prolonged exposure to high GH levels exerts on the activation of insulin signaling in the heart. For this purpose, $\mathrm{GH}$-overexpressing transgenic mice were used as a model of chronic exposure to elevated GH levels. Mice received an acute insulin stimulus and the activation of the principal signaling pathways activated by this hormone was evaluated.

\section{Materials and methods}

\section{Animals}

Transgenic mice (Mus musculus) containing the bovine $\mathrm{GH}(b G H)$ gene fused to control sequences of the rat phosphoenolpyruvate carboxykinase (PEPCK) gene have been described previously (McGrane et al. 1990). The hemizygous transgenic mice were derived from a founder male generously provided by Dr Thomas Wagner and were produced by mating transgenic males with normal C57BL/6× C3H F1 hybrid females purchased from the Jackson Laboratory (Bar Harbor, ME, USA). Mating produced approximately equal numbers of transgenic and normal progeny. Normal siblings of transgenic mice were used as controls.

Transgenic animals had markedly accelerated postweaning growth, leading to a significant increase in body weight. The mice were housed three to five per cage in a room with controlled light (12 h light/day) and temperature $\left(22 \pm 2{ }^{\circ} \mathrm{C}\right)$. The animals had free access to food (Lab Diet Formula 5001 containing a minimum of $23 \%$ protein, $4.5 \%$ fat, and a maximum of $6 \%$ crude fiber, from Purina Mills, Inc., St Louis, MO, USA) and tap water. The total number of animals used was 26 (13 transgenic and 13 normal littermates). The experimental procedure was in compliance with federal and local laws and approved by the Southern Illinois University Animal Care and Use Committee.

\section{Materials and reagents}

The reagents and apparatus for SDS-PAGE and immunoblotting were obtained from Bio-Rad. The anti-phospho-tyrosine (PY99), anti-IR $\beta$ subunit (antiIR, C-19), anti-glucose transporter 1 (GLUT1; H-43), anti-p38 $\alpha$ MAPK (C-20), anti-p38 MAPK phosphorylated at $\mathrm{Thr}^{180} / \mathrm{Tyr}^{182}$, anti-rabbit IgG conjugated with HRP, and anti-mouse IgG-HRP antibodies were purchased from Santa Cruz Biotechnology, Inc. (Santa Cruz, CA, USA). The anti-IRS1, anti-GLUT4, and antip85 subunit of PI3K antibodies were purchased from Upstate Biotechnology (Lake Placid, NY, USA). The anti-phospho-AKT $\left(\mathrm{Ser}^{473}\right)$ antibody; anti-AKT antibody that detects endogenous levels of total AKT1, AKT2, and AKT3 proteins; anti-phospho-Erk1/2 antibody that detects Erk1 and Erk2 (p44 and p42 MAPK respectively) when phosphorylated at $\mathrm{Thr}^{202}$ and $\mathrm{Tyr}^{204}$; the anti-Erk1/2 antibody; the anti-mTOR antibody; the anti-phospho-mTOR antibody that detects mTOR 
when phosphorylated at $\mathrm{Ser}^{2448}$; the anti-IRS1; antiphospho-IRS1 Ser ${ }^{612}$; and anti-phospho-IRS1 Ser ${ }^{636 / 639}$ antibodies were purchased from Cell Signaling (Beverly, MA, USA). The remaining reagents were purchased from Sigma-Aldrich.

\section{Acute insulin stimulation and tissue collection}

Female adult animals (7-8 months old) were used. Mice were starved overnight and anesthetized with ketamine/xylazine mixture. After anesthesia was induced, the inferior vena cava was exposed and $10 \mathrm{IU}$ porcine insulin per kilogram of body weight in normal saline $(0.9 \% \mathrm{w} / \mathrm{v} \mathrm{NaCl})$ were injected. Additional mice were injected with saline to evaluate basal conditions. Two minutes after injection, the heart was removed, frozen, and kept at $-80^{\circ} \mathrm{C}$ until analysis. Ten normal and ten transgenic mice were used, five individuals per group received insulin and the others received saline.

\section{Histological examination}

Additional mice (three normal and three transgenic) were used for histological analysis. The whole hearts were cut from apex to base, fixed in $10 \% \mathrm{v} / \mathrm{v}$ formalin and embedded in paraffin. Four- $\mu \mathrm{m}$ tissue sections were deparaffinized, stained with Masson's trichrome staining, and examined for myocardial fibrosis, using an Olympus BX-51 microscope equipped with a digital camera Olympus QColor 3 (Olympus, Tokyo, Japan). In ten randomly selected high power fields, the degree of fibrosis was estimated by the calculation of the percentage of blue-stained area corresponding to fibrosis in relation to the total heart area using ImagePro Plus 4.5 software (Media Cybernetics, Inc., Silver Spring, MD, USA).

\section{Glycemia and insulinemia determination}

The fasting glycemia and insulinemia levels were measured in blood using the blood One Touch Ultra 2 (Lifescan, Inc., Milpitas, CA, USA) and the insulin ultrasensitive mouse-specific ELISA (Crystal Chem, Downers Grove, IL, USA) respectively. The homeostatic model of insulin resistance (HOMA-IR) was used to assess whole-body insulin resistance using the calculation (fasting glycemia $(\mathrm{mg} / \mathrm{dl}) \times$ fasting insulinemia $(\mu \mathrm{IU} / \mathrm{ml}) / 405)$, which was originally described for humans (Matthews et al. 1985), but is also used for rodents (Vieira et al. 2009).

\section{Tissue solubilization and immunoprecipitation}

The entire heart was homogenized in solubilization buffer containing $1 \% \mathrm{w} / \mathrm{v}$ Triton together with phosphatase and protease inhibitors as described previously (Giani et al. 2008). Heart extracts were centrifuged at $100000 \mathrm{~g}$ for $1 \mathrm{~h}$ at $4{ }^{\circ} \mathrm{C}$ to eliminate insoluble material, and protein concentration in the supernatants was measured using the BCA assay (BCA Protein Assay Reagent, Thermo Scientific Pierce, Rockford, IL, USA). An aliquot of solubilized heart was diluted in Laemmli buffer, boiled for $5 \mathrm{~min}$, and stored at $-20{ }^{\circ} \mathrm{C}$ until immunoblotting.

For immunoprecipitation, equal amounts of solubilized heart protein $(2 \mathrm{mg}$ total protein in a final volume of $0.2 \mathrm{ml}$ ) were incubated at $4{ }^{\circ} \mathrm{C}$ overnight with anti-IR or anti-IRS1 antibodies at a final concentration of $4 \mu \mathrm{g} / \mathrm{ml}$. After incubation, $15 \mu \mathrm{l}$ protein A-Sepharose $50 \% \mathrm{v} / \mathrm{v}$ (Sigma Chemical Co.) were added to the mixture. Additional samples were incubated in the absence of immunoprecipitating antibody in order to corroborate that the precipitated proteins were specifically recognized by the immunoprecipitating antibody and not by protein A-Sepharose. The preparation was further incubated with constant rocking for $2 \mathrm{~h}$ at $4{ }^{\circ} \mathrm{C}$ and then centrifuged at $1000 \mathrm{~g}$ for $30 \mathrm{~s}$. The supernatant was discarded and the precipitate was washed three times with buffer containing $0.05 \mathrm{~mol} / \mathrm{l}$ Tris, $0.01 \mathrm{~mol} / \mathrm{l}$ sodium vanadate, and $1 \% \mathrm{w} / \mathrm{v}$ Triton X-100 $(\mathrm{pH} \mathrm{7 \cdot 4)}$. The final pellet was resuspended in $50 \mu \mathrm{l}$ Laemmli buffer, boiled for $5 \mathrm{~min}$, and stored at $-20^{\circ} \mathrm{C}$ until electrophoresis.

\section{Western blotting analysis}

Samples were subjected to electrophoresis in SDSpolyacrylamide gels using Bio-Rad Mini Protean apparatus (Bio-Rad Laboratories). Equal amount of total protein was loaded in each lane. Electrotransference of proteins from gel to polyvinylidene difluoride membranes was performed for $1 \mathrm{~h}$ at $100 \mathrm{~mA}$ per transferred membrane (constant current) using the V20-SDB semidry blotting apparatus (Scie-Plas, Cambridge, UK) in $0.025 \mathrm{~mol} / \mathrm{l}$ Tris, $0.192 \mathrm{~mol} / \mathrm{l}$ glycine, $20 \%$ (v/v) methanol, and $0.03 \%(\mathrm{w} / \mathrm{v})$ SDS ( $\mathrm{pH} \mathrm{8.3)}$. To reduce non-specific antibody binding, membranes were incubated for $1 \mathrm{~h}$ at room temperature in T-TBS buffer $(0.01 \mathrm{~mol} / \mathrm{l}$ Tris- $\mathrm{HCl}, 0 \cdot 15 \mathrm{~mol} / 1 \mathrm{NaCl}$, and $0.02 \% \mathrm{w} / \mathrm{v}$ Tween 20, pH 7.6) containing $3 \% \mathrm{w} / \mathrm{v}$ BSA. The membranes were then incubated overnight at $4{ }^{\circ} \mathrm{C}$ with the primary antibody. After washing with T-TBS, the membranes were incubated with a secondary antibody conjugated with HRP for $1 \mathrm{~h}$ at room temperature and washed in T-TBS. Immunoreactive proteins were revealed by enhanced chemiluminescence (ECL-Plus, Amersham Biosciences). Band intensities were quantified using Gel-Pro Analyzer 4.1 software (Media Cybernetics). To reprobe with other antibodies, the membranes were washed with acetonitrile for $10 \mathrm{~min}$ and then incubated in stripping 
buffer $(2 \% \mathrm{w} / \mathrm{v}$ SDS, $0 \cdot 1 \mathrm{~mol} / 1$ 2-mercaptoethanol, $0 \cdot 0625 \mathrm{~mol} / 1$ Tris-HCl, $\mathrm{pH} 6 \cdot 7$ ) for $40 \mathrm{~min}$ at $50{ }^{\circ} \mathrm{C}$ while shaking, washed with deionized water, and blocked with BSA.

To determine the tyrosine phosphorylation of IR and IRS1, the corresponding immunoprecipitates were analyzed by western blotting using anti-phosphoTyr antibody (1:1000). The serine phosphorylation of IRS1 was determined by western blotting with antiphospho-IRS1 Ser ${ }^{612}$ or Ser ${ }^{636 / 639}$ antibodies (1:1000) of samples previously immunoprecipitated with antiIRS1 antibody. Membranes were reblotted with anti-IR $(1: 4000)$ or anti-IRS1 $(1: 1000)$ to determine the total abundance of these signaling proteins. To determine the amount of the p85 subunit of PI3K associated with IRS1, membranes corresponding to anti-IRS1 immunoprecipitates were incubated with anti-p85 antibody (1:2000).

To determine the phosphorylation levels of AKT, mTOR, MAPKs p38, and Erk1/2, and the total protein abundance of GLUT4 and GLUT1, equal amounts of solubilized proteins in Laemmli buffer were resolved by SDS-PAGE and subjected to immunoblotting with anti-phospho-AKT, anti-phospho-mTOR, anti-phosphoErk1/2, anti-phospho-p38 MAPK, anti-GLUT4, or antiGLUT1 (1:1000 dilutions for all antibodies). Cardiac AKT, mTOR, Erk1/2, and p38 MAPK protein abundance was detected by reprobing the corresponding membranes with the specific antibodies (1:1000).

To better detect the basal phosphorylation levels of IR, IRS1, and AKT and the basal association between IRS1 and p85, it was necessary to run separate experiments with twofold protein loading.

\section{Statistical analysis}

Experiments were performed analyzing all groups of animals in parallel, $n$ representing the number of different individuals used in each group. Results are presented as mean \pm s.E.M. of the number of samples indicated. Statistical analyses were performed by twoway ANOVA followed by the Bonferroni post-test using the GraphPad Prism 4 statistical program by the GraphPad Software, Inc. (San Diego, CA, USA). Student's $t$-test was used when the values of two groups were analyzed. Data were considered significantly different if $P<0 \cdot 05$.

\section{Results}

\section{Animal characteristics}

The characteristics of GH overexpressing transgenic mice and their normal littermates are shown in Table 1. As expected, basal hyperinsulinemia with
Table 1 Characteristics of mice overexpressing GH and normal controls. Data are presented as mean value \pm S.E.M. $(n=12)$

\begin{tabular}{llll} 
& \multicolumn{1}{c}{ Normal } & & GH transgenic \\
\cline { 2 - 2 } Glycemia $(\mathrm{mg} / \mathrm{dl})$ & & \\
Insulinemia $(\mu \mathrm{lU} / \mathrm{ml})$ & $126 \pm 6^{\mathrm{a}}$ & & $135 \pm 5^{\mathrm{a}}$ \\
HOMA-IR & $16 \pm 4^{\mathrm{a}}$ & & $95 \pm 33^{\mathrm{b}}$ \\
Body weight $(\mathrm{g})$ & $5 \cdot 0 \pm 0 \cdot 4^{\mathrm{a}}$ & & $31 \cdot 7 \pm 3 \cdot 5^{\mathrm{b}}$ \\
Heart weight $(\mathrm{mg})$ & $34 \pm 2^{\mathrm{a}}$ & & $48 \pm 2^{\mathrm{b}}$ \\
Heart wt/body wt $(\%)$ & $114 \pm 4^{\mathrm{a}}$ & & $240 \pm 9^{\mathrm{b}}$ \\
& $0.34 \pm 0 \cdot 01^{\mathrm{a}}$ & & $0.51 \pm 0 \cdot 01^{\mathrm{b}}$ \\
\hline
\end{tabular}

HOMA-IR, homeostatic model of insulin resistance. Different letters (a and b) denote significant differences at $P<0.001$ versus normal mice.

normoglycemia was corroborated in transgenic mice, in line with previous reports (Dominici et al. 1998, $1999 a)$. In addition, HOMA-IR score was significantly increased in GH transgenic mice, indicating wholebody insulin resistance.

In accordance with other publications (Bollano et al. 2000, Colligan et al. 2002), GH transgenic mice exhibited an increase in both body and heart weight compared with non-transgenic mice, but the heart weight remained significantly increased even after normalization to body weight, indicating hypertrophy and therefore a state of cardiomegaly.

The degree of fibrosis was estimated by the determination of the extracellular matrix content using Masson's trichrome staining showing fibrosis with blue color. Transgenic mice developed perivascular and interstitial myocardial fibrosis, while normal extracellular matrix content was observed in nontransgenic mice (Fig. 1A-D). Image quantification indicated a significant increase in the myocardial fibrosis in transgenic mice (Fig. 1E). Increased interstitial fibrosis in $\mathrm{GH}$ transgenic mice had been previously reported (Bollano et al. 2000).

\section{Tyrosine phosphorylation and protein levels of IR}

Insulin binding to its membrane receptor triggers the autophosphorylation of the $\beta$ subunits of the IR in tyrosine residues, which results in further activation of its tyrosine kinase activity and in the creation of docking sites for intracellular signaling mediators. Insulin stimulation induced a marked increase in the tyrosine phosphorylation of the IR in the heart, both in normal and in transgenic animals (Fig. 2A). No differences in the insulin-induced phosphorylation of the IR (Fig. 2A) or in the protein content (Fig. 2B) were observed between transgenic and normal mice. To better discriminate the basal phosphorylation levels of this protein, solubilized hearts were run in separate experiments with twofold protein loading. As shown in Fig. 2C, transgenic mice exhibited a significant 


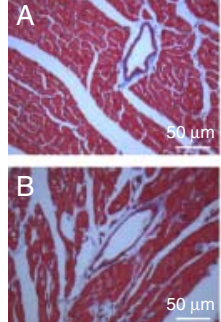

Normal

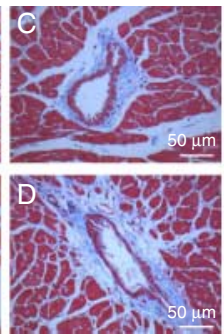

$\mathrm{GH}$ transgenic
E

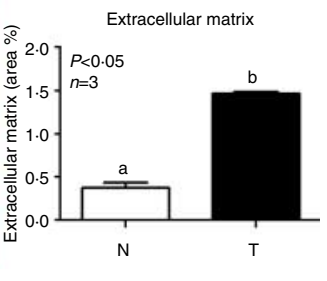

Figure 1 Myocardial fibrosis evaluation by Masson's trichrome staining. Representative histological sections showing in blue staining the cardiac extracellular matrix content in normal $(\mathrm{N})$ ( $A$ and $B$ ) and $\mathrm{GH}$ transgenic $(\mathrm{T})(\mathrm{C}$ and $\mathrm{D})$ mice $(400 \times)$. The percentage of blue-stained area corresponding to fibrosis in relation to the total heart area is shown in panel $\mathrm{E}$. Data are the mean \pm S.E.M., three different individuals of each group were analyzed in parallel. Groups denoted by different letters are significantly different, $P<0.05$. Full colour version of this is figure available via http://dx.doi.org/10.1530/JME-11-0066.

increase in IR basal phosphorylation compared with normal mice, probably as a result of the continuous exposure to hyperinsulinemia.

\section{Tyrosine phosphorylation and protein levels of IRS1}

The activated IR phosphorylates different signaling mediators, including the IRS. IRS1 is believed to be the most important IRS involved in insulin stimulation of cardiac growth (DeBosch \& Muslin 2008). The phosphorylation of IRS1 on tyrosine residues is required for insulin-induced responses. Insulin stimulation clearly induced IRS1 tyrosine phosphorylation in normal and transgenic mice. However, transgenic mice exhibited a significant reduction ( $\sim 25 \%$ decrease $)$ in the response to insulin compared with non-transgenic animals (Fig. 2D). There were no significant differences in the IRS1 protein content between normal and transgenic animals (Fig. 2E), indicating that the diminished tyrosine phosphorylation levels of IRS1 are not a consequence of a decrease in the protein abundance of this intracellular mediator. As described for the IR, transgenic mice exhibited higher basal IRS1 tyrosine phosphorylation level than normal controls (Fig. 2F).

\section{IRS1-associated p85 regulatory subunit of PI3K}

Once phosphorylated on tyrosine residues, IRS1 associates with the regulatory subunit of PI3K (p85), inducing the activation of the p110 catalytic subunit of the enzyme. Insulin stimulation induced a significant increase in the association of p85 with IRS1, but this association was $50 \%$ lower in transgenic mice compared with normal animals (Fig. 3A). The total protein content of p85 in heart extracts was similar in normal and transgenic mice (Fig. 3B). In line with the results obtained for IRS1 tyrosine phosphorylation, its basal association with $\mathrm{p} 85$ was significantly increased in transgenic mice (Fig. 3C).
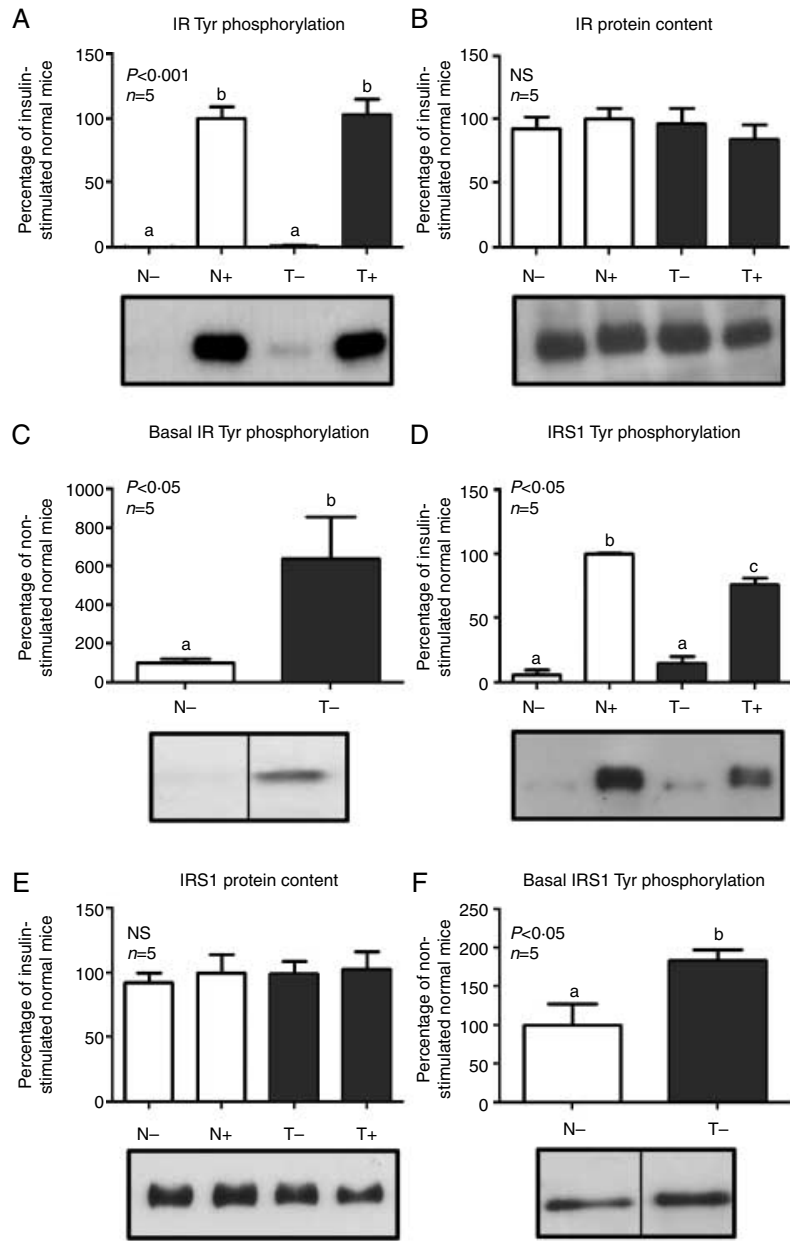

Figure 2 Insulin receptor (IR) and insulin receptor substrate 1 (IRS1) tyrosine phosphorylation and protein content. Normal (N) and $\mathrm{GH}$ transgenic $(\mathrm{T})$ mice were injected with saline $(-)$ or insulin $(+)$ and the heart was removed after 2 min. Equal amounts of solubilized heart protein were immunoprecipitated with an antibody to the $\beta$-subunit of the IR (anti-IR) and subjected to immunoblot analysis using an anti-phospho-Tyr (A and $\mathrm{C}$ ) or antiIR (B) antibodies or were immunoprecipitated with anti-IRS1 antibody and subjected to immunoblot analysis using an antiphospho-Tyr (D and F) or anti-IRS1 (E) antibodies. When basal and insulin-stimulated samples were run together, the high intensity of the band corresponding to insulin-stimulated phosphorylation blunted the signal corresponding to basal phosphorylation in non-stimulated mice, rendering it almost undetectable (A and D). To better discriminate differences observed in basal tyrosine phosphorylation levels, separate experiments with twofold protein loading were performed ( $C$ and F). Data are the mean \pm S.E.M. of five subsets of different individuals. Groups denoted by different letters are significantly different; NS, not significant. Representative immunoblots are shown. 

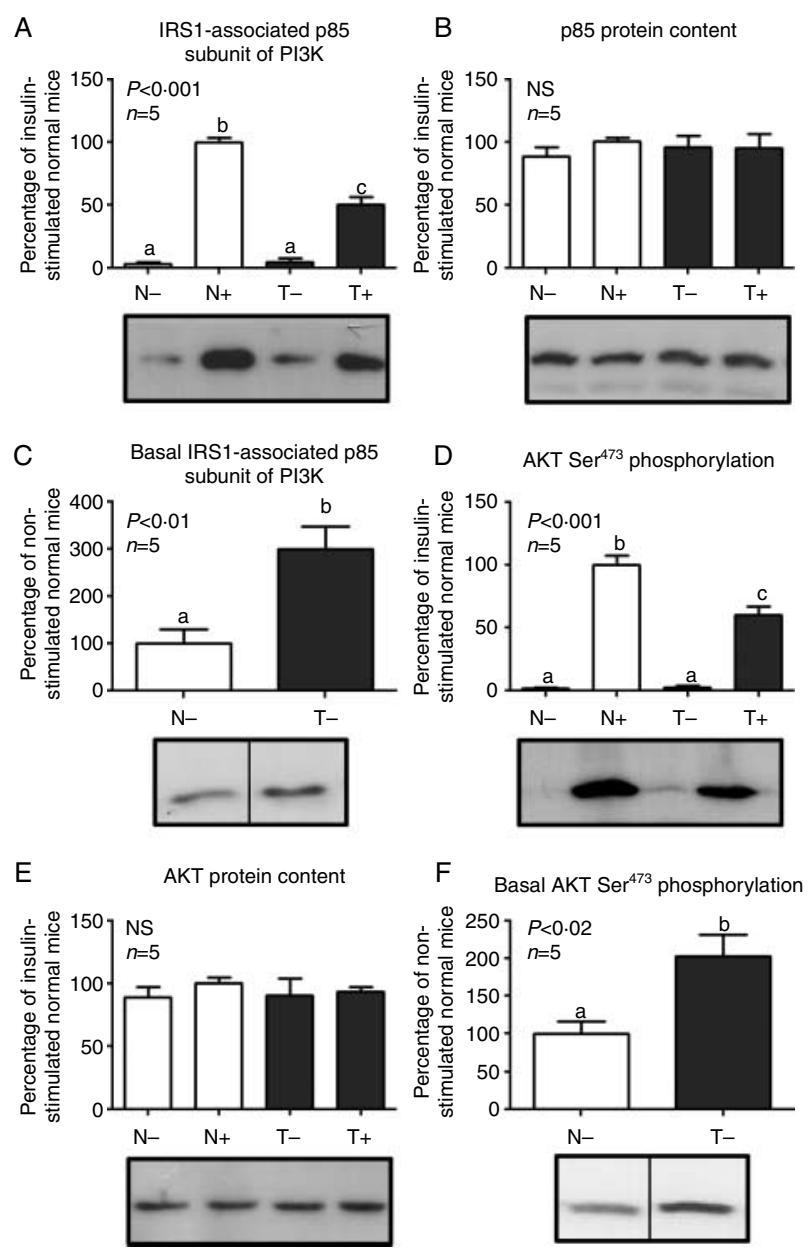

Figure 3 Association of insulin receptor substrate 1 (IRS1) with the p85 subunit of phosphatidylinositol 3-kinase (PI3K) and serine phosphorylation of AKT. Normal $(\mathrm{N})$ and $\mathrm{GH}$ transgenic (T) mice were injected with saline $(-)$ or insulin $(+)$ and the heart was removed after 2 min. Equal amounts of solubilized heart protein were immunoprecipitated with anti-IRS1 antibody and subjected to immunoblot analysis using an anti-p85 antibody ( $\mathrm{A}$ and $\mathrm{C})$. To evaluate p85 protein content, solubilized hearts were directly subjected to immunoblotting with anti-p85 antibody (B). To analyze AKT, equal amounts of solubilized heart protein were directly subjected to immunoblotting using an anti-phospho-AKT Ser ${ }^{473}$ (D and F) or anti-AKT (E) antibodies. To better discriminate differences observed in basal association between IRS1 and p85 or basal AKT phosphorylation, separate experiments with twofold protein loading were performed ( $C$ and F). Data are the mean \pm S.E.M. of five subsets of different individuals. Groups denoted by different letters are significantly different; NS, not significant. Representative immunoblots are shown.

\section{AKT serine phosphorylation and protein levels}

AKT, also known as protein kinase B (PKB), is activated by insulin via the PI3K signaling pathway. The phosphorylation of AKT at Ser ${ }^{473}$, an activating residue, was induced by insulin stimulation in normal and transgenic mice, albeit a $40 \%$ decrease was evident in transgenic mice (Fig. 3D). The protein levels of AKT were not altered by either genotype or insulin stimulation (Fig. 3E). As shown in Fig. 3F, transgenic mice exhibited a twofold increase in AKT basal phosphorylation compared with normal mice.

\section{mTOR phosphorylation and protein levels}

Many growth factors and hormones, including insulin, activate mTOR by phosphorylation at $\mathrm{Ser}^{2448}$ via the PI3K/AKTsignaling pathway (Dann et al. 2007). As shown in Fig. 4A, no significant differences in mTOR phosphorylation were detected after acute insulin stimulation under the experimental conditions used. Transgenic mice exhibited augmented mTOR basal phosphorylation (Fig. 4A) and higher mTOR protein content than normal siblings (Fig. 4B); moreover, the ratio of mTOR phosphorylation to mTOR protein abundance was significantly increased in transgenic mice (Fig. 4C).

\section{GLUT1 and GLUT4 protein levels}

The uptake of extracellular glucose by cardiomyocytes is regulated by the content and activity of two GLUTs at the plasma membrane, namely, GLUT1 and GLUT4, of which GLUT4 is the most abundant (Coort et al. 2007, Muniyappa et al. 2007). The total amount of these GLUTs was analyzed in solubilized heart extracts. While no significant differences were detected for GLUT1 (Fig. 5A), GLUT4 protein content was $~ 40 \%$ decreased in transgenic mice compared with normal controls (Fig. 5B).

\section{MAPKs phosphorylation and protein levels}

The MAPKs are involved in cell growth, mitogenesis, and differentiation (DeBosch \& Muslin 2008). Erk1 and Erk2 ( 44 and $42 \mathrm{kDa}$ respectively) are activated by

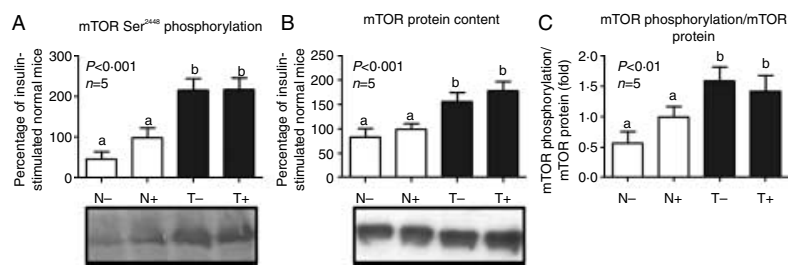

Figure 4 mTOR phosphorylation and protein content. Normal (N) and $\mathrm{GH}$ transgenic $(\mathrm{T})$ mice were injected with saline $(-)$ or insulin $(+)$ and the heart was removed after 2 min. Equal amounts of solubilized heart protein were subjected to immunoblot analysis using an anti-phospho-mTOR $\operatorname{Ser}^{2448}$ (A and C) or anti-mTOR (B) antibodies. The ratio of phospho-mTOR to mTOR protein content is shown in panel C. Data are the mean \pm S.E.M. of five subsets of different individuals, run in two separate experiments.

Groups denoted by different letters are significantly different. Representative immunoblots are shown. 


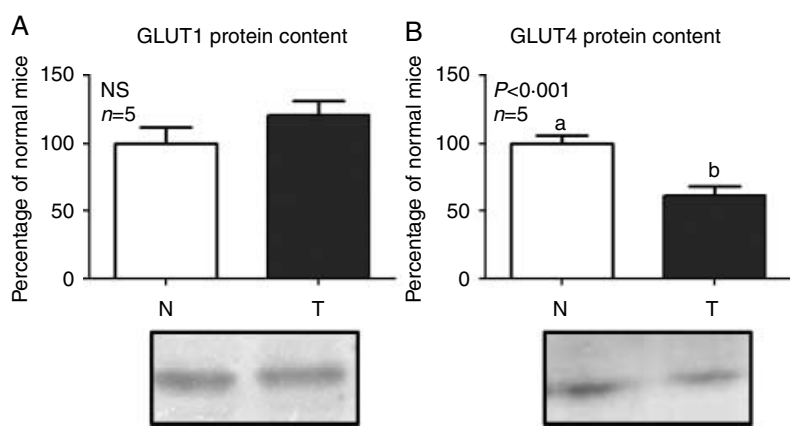

Figure 5 Glucose transporters (GLUT) 1 and 4 protein content. Equal amounts of solubilized heart from normal $(\mathrm{N})$ and $\mathrm{GH}$ transgenic $(T)$ mice were subjected to immunoblot analysis using an anti-GLUT1 (A) or anti-GLUT4 (B) antibodies. Data are the mean \pm S.E.M. of five subsets of different individuals, run in two separate experiments. Groups denoted by different letters are significantly different; NS, not significant. Representative immunoblots are shown.

phosphorylation at $\mathrm{Thr}^{202} / \mathrm{Tyr}^{204}$. The p38 MAPKs, a subfamily of stress-activated protein kinases, are activated by phosphorylation at $\mathrm{Thr}^{180} / \mathrm{Tyr}^{182}$ in response to various extracellular stimuli, including inflammatory cytokines and growth factors (Wang 2007). Insulin was reported to induce the activation of these MAPKs but with a slower kinetic than that of the IRS1/PI3K signaling pathway, normally requiring longer times to detect an increase in the phosphorylation of the MAPKs on activating residues (Carvalheira et al. 2005). We therefore determined the basal phosphorylation of the MAPK Erk1/2 and p38 in normal and GH transgenic mice not stimulated with insulin. The basal phosphorylation of Erk1/2 was not significantly altered in transgenic mice compared with normal littermates (Fig. 6A). However, basal p38 MAPK phosphorylation was elevated in transgenic mice (Fig. 6C). No differences in the protein content of the MAPKs in the study were detected between normal and transgenic mice (Fig. 6B and D).

\section{Phosphorylation of IRS1 at inhibitory serine residues}

Ser/Thr phosphorylation of IRS proteins may interfere with IRS binding to the IR, induce IRS degradation, or inhibit the association with downstream effectors, depending on the localization of the phosphorylated residue on IRS (Draznin 2006, Boura-Halfon \& Zick 2009). To address whether this could be a mechanism involved in the negative modulation of insulin signaling in GH transgenic mice, the levels of IRS1 phosphorylation at serine inhibitory residues were determined. As shown in Fig. 7, transgenic mice displayed enhanced phosphorylation of IRS1 at $\operatorname{Ser}^{612}$ and $\operatorname{Ser}^{636 / 639}$ compared with normal littermates.

\section{Discussion}

The mechanisms implicated in the cardiac dysfunction observed in acromegaly are not completely elucidated. Numerous experimental and clinical findings indicate that chronic elevation in circulating GH exerts antiinsulin effects. Insulin regulates various aspects of metabolism and cardiovascular function, including glucose and fatty acid metabolism, protein translation, cell growth, and vascular tone (Muniyappa et al. 2007, Bertrand et al. 2008, DeBosch \& Muslin 2008). The main signaling cascades activated by insulin are the MAPK and the PI3K/AKT signaling pathways. The MAPK pathway plays a prominent role in the regulation of transcriptional and mitogenic processes, such as growth, proliferation, differentiation, and gene expression, while the PI3K pathway is involved in the metabolic actions of insulin as well as in cardiac growth (Coort et al. 2007, Bertrand et al. 2008, Xu \& Messina 2009). GH seems to modulate insulin sensitivity by several mechanisms that have not yet been completely elucidated and may act in concert to induce insulin resistance. A mechanism that may participate in the insulin resistance observed under chronic GH excess is
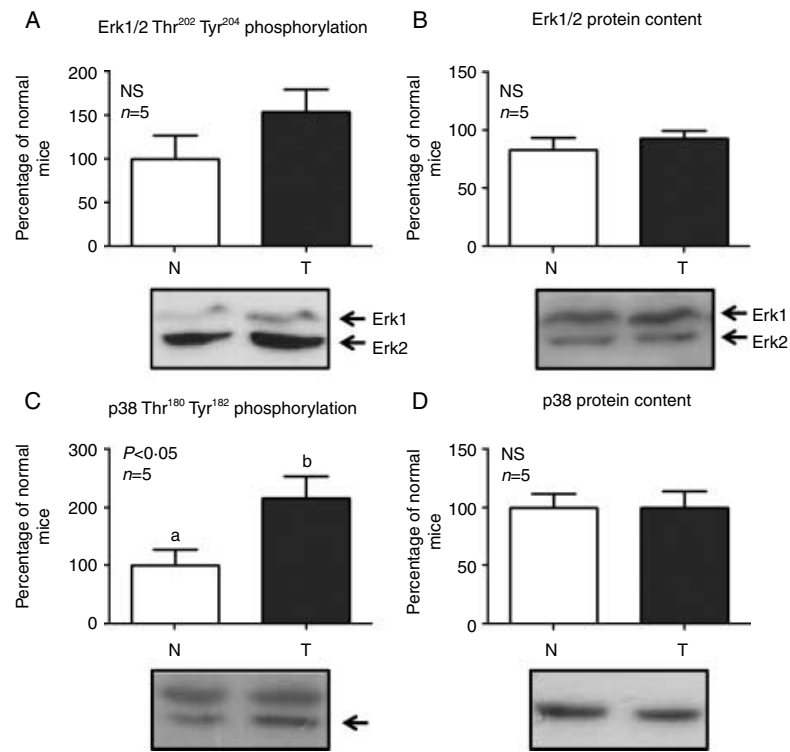

Figure 6 Erk1/2 and p38 MAPKs phosphorylation and protein content. Equal amounts of solubilized heart from normal $(\mathrm{N})$ and $\mathrm{GH}$ transgenic $(\mathrm{T})$ mice were subjected to immunoblot analysis using an anti-phospho-Erk1/2 $\mathrm{Thr}^{202} \mathrm{Tyr}^{204}(\mathrm{~A})$, anti-Erk1/2 (B), anti-phospho-p38 $\mathrm{Thr}^{180} \mathrm{Tyr}^{182}(\mathrm{C})$, or anti-p38 MAPK antibodies. In panels $\mathrm{A}$ and $\mathrm{B}$, the bands corresponding to Erk1 and Erk2 were analyzed together. In panel $C$, the arrow indicates the analyzed phosphorylation band, which corresponds to the p38 protein band detected in panel D. Data are the mean \pm S.E.M. of five subsets of different individuals run in two separate experiments. Groups denoted by different letters are significantly different; NS, not significant. Representative immunoblots are shown. 


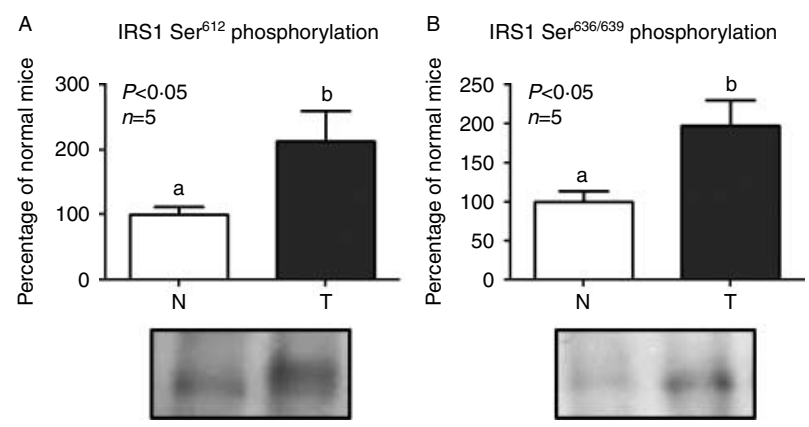

Figure 7 Insulin receptor substrate 1 (IRS1) serine phosphorylation. Equal amounts of solubilized heart from normal $(\mathrm{N})$ and $\mathrm{GH}$ transgenic $(\mathrm{T})$ mice were immunoprecipitated with anti-IRS1 antibody and subjected to immunoblot analysis using antiphospho-IRS1 Ser ${ }^{612}(A)$ or anti-phospho-IRS1 Ser ${ }^{636 / 639}$ (B) antibodies. Data are the mean \pm S.E.M. of five subsets of different individuals run in two separate experiments. Groups denoted by different letters are significantly different. Representative immunoblots are shown.

the ability of GH to interfere with post-receptor insulin signaling. These two hormones can directly interact by signaling cross talk, and prolonged exposure to $\mathrm{GH}$ was shown to alter the abundance and activity of several insulin-signaling mediators (Dominici et al. 2005, Xu \& Messina 2009).

Rodent models of chronic GH excess are useful tools to investigate the mechanisms of $\mathrm{GH}$-induced insulin resistance. Mice overexpressing GH constitute a model of gigantism/acromegaly, presenting high continuous GH levels since birth, with a consequent increase in body size and organomegaly, including cardiomegaly. These animals also have metabolic alterations including basal hyperinsulinemia with normoglycemia, a reflection of an insulin-resistant state (Valera et al. 1993, Kopchick et al. 1999, Bartke 2003). Recent findings showed that male GH transgenic mice exhibit a reduced conversion of pyruvate to glucose as well as an improved glucose and insulin tolerance, in comparison to their normal littermates (Boparai et al. 2010). On the contrary, the female GH transgenic mice from the strain used in the current work displayed similar whole-body sensitivity to insulin as normal controls, as assayed by insulin tolerance test, concomitant with a slightly better glucose disposal after a glucose load (Boparai et al. 2010). The apparent improvement in glucose metabolism could be attributable to a marked compensatory increase in insulin secretion during the glucose tolerance test and to a favorable body composition (i.e. increased lean body mass and decreased body fat mass). Thus, even though GH transgenic mice may display improved glucose tolerance, this occurs under a scenery of hyperinsulinemia possibly due to enhanced $\beta$-cell function generating the capacity of releasing more insulin in the face of a glucose challenge. The good performance in the insulin tolerance test could be related to the higher percentage of muscle mass that transgenic mice exhibit, which may overcome the peripheral resistance to insulin.

Our group has previously reported alterations in several components of the insulin-signaling system in liver and skeletal muscle of female GH transgenic mice from the line used in the current study. In the liver, GH excess was associated with a decrease in the content of IR with a simultaneous increase in its basal activity, along with basal activation of the IR/IRS1/PI3K pathway, which was unresponsive to further stimulation by exogenous insulin in transgenic mice (Dominici et al. 1998, 1999a). In skeletal muscle, GH transgenic mice displayed decreased IR protein levels and a decline in insulin-induced activation of IR/IRS1/PI3K signaling pathway, along with increased protein content of p85, which was postulated to play a negative role in insulin signaling (Dominici et al. 1999b, 2005, Barbour et al. 2005). It was therefore of interest to evaluate whether insulin signaling was also impaired in the heart of mice overexpressing $\mathrm{GH}$ given the reported deleterious effects of GH excess in the cardiovascular system.

Our current results indicate that $\mathrm{GH}$ transgenic mice exhibit impaired insulin signaling in the heart. In response to acute exogenous insulin stimulation, the activation of IRS1/PI3K/AKT signaling cascade was significantly decreased compared with normal controls. The impaired insulin signal was not caused by a reduction in the protein levels of IR or by alterations in its insulin-induced tyrosine phosphorylation in the cardiac tissue, suggesting that mechanisms downstream of the IR were involved. Although no differences in the protein content levels of IRS1, p85, and AKT were detected, acute insulin stimulation of these mediators was impaired. Moreover, basal activation of IRS1/PI3K/ AKT and p38 MAPK signaling pathways was detected in transgenic mice heart. Therefore, as previously reported in the liver and skeletal muscle of GH transgenic mice (3- to 5-month-old females; Dominici et al. 1999a,b), insulin signaling is impaired in the heart of the GH transgenic mice used in the current study (7- to 8-month-old females), but the molecular alterations observed are different, which may be a reflection of distinct underlying mechanisms in each tissue. However, we cannot rule out that the different age of the animals used in the previous studies on liver and muscle and in this study in heart may be a factor that influences the molecular alterations observed.

Insulin resistance has been mainly associated with defects at the post-receptor level of insulin signaling, with IR levels either normal or slightly diminished in patients and animal models (Draznin 2006). One of the molecular mechanisms described is the disruption of the balance between PI3K subunits (i.e. p85, the regulatory subunit and p110, the catalytic subunit) 
due to increased expression of $\mathrm{p} 85 \alpha$, leading to an excess of free $\mathrm{p} 85 \alpha$ subunit that competes with the p85-p110 complex for binding sites on tyrosinephosphorylated IRS1. GH excess is one of the possible causes of imbalance between PI3K subunits (Dominici et al. 1999b, 2005, Barbour et al. 2005, Draznin 2006); however, this would apparently not be the case in the heart of GH transgenic mice, as no differences in the total protein levels of $\mathrm{p} 85$ were detected.

Chronic hyperinsulinemia has been associated with insulin resistance, both as a compensatory mechanism to the peripheral insulin resistance and as an etiological mechanism per se (Rizza et al. 1985, Ueno et al. 2005). Prolonged insulin stimulation and other stimuli related to insulin resistance activate Ser/Thr kinases that phosphorylate IRS proteins, inhibiting their function and interfering with insulin signaling (Draznin 2006, Boura-Halfon \& Zick 2009). mTOR is one of the kinases downstream of the PI3K/AKT pathway that is activated on prolonged insulin stimulation and has been implicated in the downregulation of insulin signaling, acting as a negative feedback control mechanism (Ueno et al. 2005, Draznin 2006, Bertrand et al. 2008, Boura-Halfon \& Zick 2009). Increased activity and protein expression of mTOR has been related to impaired insulin signaling and serine phosphorylation of IRS proteins in hyperinsulinemic rats (Ueno et al. 2005). GH transgenic mice are hyperinsulinemic and exhibit cardiac basal activation of IRS1/PI3K/AKT pathway along with mTOR upregulation, which may be implicated in the insulin desensitization observed in these mice. In fact, increased basal phosphorylation levels of IRS1 at Ser ${ }^{612}$ and Ser ${ }^{636 / 639}$ were detected in GH transgenic mice heart. These serine residues are located at the carboxy-terminal tail of IRS1 and their phosphorylation would inhibit the ability of downstream effectors to bind to specific tyrosine residues in IRS1, including p85 (Boura-Halfon \& Zick 2009). Although the MAPKs were reported to play a major role in the phosphorylation of these serine residues after short-term insulin treatment, mTOR seems to have a prominent role in their phosphorylation following prolonged insulin stimulation (Gual et al. 2003). However, the participation of other kinases in the IRS1 serine phosphorylation observed cannot be ruled out, as several Ser/Thr kinases may phosphorylate the same residues (Boura-Halfon \& Zick 2009).

Hyperinsulinemia is believed to facilitate cardiac hypertrophy by over-activating insulin signaling in the heart (Bertrand et al. 2008, Yu et al. 2010). Chronic stimulation of the MAPK and PI3K/AKT signaling pathways has been associated with the establishment of myocardial hypertrophy (Proud 2004, Bertrand et al. 2008). In particular, the AKT/mTOR pathway has been demonstrated to play a role in insulin-mediated cardiac hypertrophy by promoting protein synthesis (Proud
2004, Patterson et al. 2009). Therefore, the basal activation of IRS1/PI3K/AKT pathway and the high levels of activated mTOR found in the heart of mice overexpressing GH may be involved in the hypertrophy observed in this animal model, while Erk $1 / 2$ would not be directly implicated, as no increase in their basal phosphorylation or protein levels were detected. Activation of p38 MAPK cascade in cardiac tissue is believed to promote cardiac fibrosis and would not be directly involved in the promotion of cardiac hypertrophy (Muslin 2008). The fibrosis detected in the heart of GH transgenic mice could, therefore, be associated with the increased activation of p38 MAPK they exhibit.

Insulin stimulation of glucose uptake in cardiac myocytes is mainly mediated by GLUT4, while GLUT1 is the principal mediator of basal glucose uptake (Coort et al. 2007, Muniyappa et al. 2007). Diabetes has been associated with GLUT4 downregulation, which was proposed to contribute to the myocardial dysfunction observed in this disease (Slieker et al. 1992, Burcelin et al. 1993, Garvey et al. 1993, Coort et al. 2007). Moreover, deficiency of GLUT4 was reported to result in cardiac hypertrophy (Katz et al. 1995, Abel et al. 1999, Zisman et al. 2000, DeBosch \& Muslin 2008). In contrast, myocardial upregulation of GLUT1 associated with increased basal glucose uptake has been described in models of cardiac hypertrophy (Abel et al. 1999). Considering this evidence, and taking into account that $\mathrm{GH}$ transgenic mice exhibited a reduction in the total protein content of GLUT4, but no significant alterations in the abundance of GLUT1 in the heart, the present results point to GLUT4 downregulation as a potential mechanism involved in the cardiac pathology observed in transgenic mice overexpressing GH.

Disruption of GH receptor in GHR-knockout (GHR$\mathrm{KO})$ mice produces $\mathrm{GH}$ resistance, extremely low levels of circulating IGF1, severe growth retardation, and dwarfism (Zhou et al. 1997, Coschigano et al. 2000). These mice present increased insulin sensitivity, as they exhibit hypoinsulinemia and hypoglycemia associated with an increment in the abundance and activity of the IRs in hepatocytes (Dominici et al. 2000, Liu et al. 2004). Previous studies from our group demonstrated that GHR-KO mice exhibit a marked increase in the activation of insulin signaling in the heart (Giani et al. 2008). The fact that mice exposed to chronically elevated GH levels exhibit cardiac insulin resistance, while mice in which the receptor of GH has been disrupted display enhanced cardiac insulin signaling, reflects the anti-insulin actions of $\mathrm{GH}$ in this tissue, and could be associated with the cardiac alterations observed in conditions of GH deficiency or excess. Interestingly, GHR-KO mice exhibit increased longevity, while the life span is significantly shortened in GH-overexpressing transgenic mice (Coschigano et al. 2000, Bartke 2003, 2005). 
In summary, chronic exposure to elevated circulating GH levels in mice was associated with impaired insulin signaling in the heart. This was evident from the defects at the post-receptor level, including decreased activation on acute insulin stimulation through the IRS1/PI3K/AKT pathways. Higher basal activation of the IR, IRS1, PI3K, as well as of the Ser/Thr kinases AKT, mTOR, and p38 was observed in GH transgenic mice, along with protein upregulation of mTOR and increased levels of serine IRS1 phosphorylation, which is regarded as an inhibitory modification. Whether these alterations are a direct consequence of the elevated GH and IGF1 levels or secondary to the resulting hyperinsulinemia or other disorders that may arise in a context of chronic GH exposure remains to be elucidated.

\section{Declaration of interest}

The authors declare that there is no conflict of interest that could be perceived as prejudicing the impartiality of the research reported.

\section{Funding}

This work was supported by the University of Buenos Aires (grant number 20020100100444) and the National Council of Scientific and Technological Research CONICET (grant number PIP 427, 2010) to D T, by the National Institute on Aging (grant numbers AG19899, AG031736) to A B, and the National Institute on Aging (grant number AG032290) to M M M. The Fulbright Commission and the CONICET awarded J G M a grant for a post-doctoral research stay at the Southern Illinois University. J G M, M C M, L G, A I S, F P D, and $\mathrm{D} T$ are Career Investigators from CONICET; J F G is a postdoctoral fellow from CONICET and BSc. C S M is a research fellow from CONICET.

\section{References}

Abel ED, Kaulbach HC, Tian R, Hopkins JC, Duffy J, Doetschman T, Minnemann T, Boers ME, Hadro E, Oberste-Berghaus C et al. 1999 Cardiac hypertrophy with preserved contractile function after selective deletion of GLUT4 from the heart. Journal of Clinical Investigation 104 1703-1714. (doi:10.1172/JCI7605)

Barbour LA, Mizanoor Rahman S, Gurevich I, Leitner JW, Fischer SJ, Roper MD, Knotts TA, Vo Y, McCurdy CE, Yakar S et al. 2005 Increased P85alpha is a potent negative regulator of skeletal muscle insulin signaling and induces in vivo insulin resistance associated with growth hormone excess. Journal of Biological Chemistry 280 37489-37494. (doi:10.1074/jbc.M506967200)

Bartke A 2003 Can growth hormone (GH) accelerate aging? Evidence from GH-transgenic mice Neuroendocrinology 78 210-216. (doi:10.1159/000073704)

Bartke A 2005 Minireview: role of the growth hormone/insulinlike growth factor system in mammalian aging. Endocrinology 146 3718-3723. (doi:10.1210/en.2005-0411)

Belke DD, Betuing S, Tuttle MJ, Graveleau C, Young ME, Pham M, Zhang D, Cooksey RC, McClain DA, Litwin SE et al. 2002 Insulin signaling coordinately regulates cardiac size, metabolism, and contractile protein isoform expression. Journal of Clinical Investigation 109 629-639. (doi:10.1172/JCI13946)
Bertrand L, Horman S, Beauloye C \& Vanoverschelde JL 2008 Insulin signalling in the heart. Cardiovascular Research 79 238-248. (doi:10.1093/cvr/cvn093)

Bollano E, Omerovic E, Bohlooly-y M, Kujacic V, Madhu B, Törnell J, Isaksson O, Soussi B, Schulze W, Fu ML et al. 2000 Impairment of cardiac function and bioenergetics in adult transgenic mice overexpressing the bovine growth hormone gene. Endocrinology 141 2229-2235. (doi:10.1210/en.141.6.2229)

Boparai RK, Arum O, Khardori R \& Bartke A 2010 Glucose homeostasis and insulin sensitivity in growth hormone-transgenic mice: a cross-sectional analysis. Biological Chemistry 391 1149-1155. (doi:10.1515/BC.2010.124)

Boura-Halfon S \& Zick Y 2009 Phosphorylation of IRS proteins, insulin action, and insulin resistance. American Journal of Physiology. Endocrinology and Metabolism 296 E581-E591. (doi:10.1152/ajpendo. 90437.2008)

Burcelin R, Printz RL, Kande J, Assan R, Granner DK \& Girard J 1993 Regulation of glucose transporter and hexokinase II expression in tissues of diabetic rats. American Journal of Physiology 265 E392-E401.

Carvalheira JB, Torsoni MA, Ueno M, Amaral ME, Araújo EP, Velloso LA, Gontijo JA \& Saad MJ 2005 Cross-talk between the insulin and leptin signaling systems in rat hypothalamus. Obesity Research 13 48-57. (doi:10.1038/oby.2005.7)

Ciulla M, Arosio M, Barelli MV, Paliotti R, Porretti S, Valentini P, Tortora G, Buonamici V, Moraschi A, Capiello V et al. 1999 Blood pressure-independent cardiac hypertrophy in acromegalic patients. Journal of Hypertension 17 1965-1969. (doi:10.1097/00004872199917121-00028)

Climent V, Marín F \& Picó A 2007 Pharmacologic therapy in growth hormone disorders and the heart. Current Medicinal Chemistry 14 1399-1407. (doi:10.2174/092986707780831195)

Colao A 2008 The GH-IGF-I axis and the cardiovascular system: clinical implications. Clinical Endocrinology 69 347-358. (doi:10. $1111 /$ j.1365-2265.2008.03292.x)

Colligan PB, Brown-Borg HM, Duan J, Ren BH \& Ren J 2002 Cardiac contractile function is enhanced in isolated ventricular myocytes from growth hormone transgenic mice. Journal of Endocrinology 173 257-264. (doi:10.1677/joe.0.1730257)

Coort SL, Bonen A, van der Vusse GJ, Glatz JF \& Luiken JJ 2007 Cardiac substrate uptake and metabolism in obesity and type-2 diabetes: role of sarcolemmal substrate transporters. Molecular and Cellular Biochemistry 299 5-18. (doi:10.1007/s11010-005-9030-5)

Coschigano KT, Clemmons D, Bellush LL \& Kopchick JJ 2000 Assessment of growth parameters and life span of GHR/BP gene-disrupted mice. Endocrinology 141 2608-2613. (doi:10.1210/ en.141.7.2608)

Dann SG, Selvaraj A \& Thomas G 2007 mTOR complex1-S6K1 signaling: at the crossroads of obesity, diabetes and cancer. Trends in Molecular Medicine 13 252-259. (doi:10.1016/j.molmed.2007.04. 002)

DeBosch BJ \& Muslin AJ 2008 Insulin signaling pathways and cardiac growth. Journal of Molecular and Cellular Cardiology 44 855-864. (doi:10.1016/j.yjmcc.2008.03.008)

Dominici FP, Balbis A, Bartke A \& Turyn D 1998 Role of hyperinsulinemia on hepatic insulin receptor concentration and autophosphorylation in the presence of high growth hormone levels in transgenic mice overexpressing growth hormone gene. Journal of Endocrinology 159 15-25. (doi:10.1677/joe.0.1590015)

Dominici FP, Cifone D, Bartke A \& Turyn D 1999 $a$ Loss of sensitivity to insulin at early events of the insulin signaling pathway in the liver of growth hormone-transgenic mice. Journal of Endocrinology 161 383-392. (doi:10.1677/joe.0.1610383)

Dominici FP, Cifone D, Bartke A \& Turyn D $1999 b$ Alterations in the early steps of the insulin-signaling system in skeletal muscle of GH-transgenic mice. American Journal of Physiology 277 E447-E454. 
Dominici FP, Arostegui Diaz G, Bartke A, Kopchick JJ \& Turyn D 2000 Compensatory alterations of insulin signal transduction in liver of growth hormone receptor knockout mice. Journal of Endocrinology 166 579-590. (doi:10.1677/joe.0.1660579)

Dominici FP, Argentino DP, Muñoz MC, Miquet JG, Sotelo AI \& Turyn D 2005 Influence of the crosstalk between growth hormone and insulin signalling on the modulation of insulin sensitivity. Growth Hormone $\mathcal{E}$ IGF Research 15 324-336. (doi:10.1016/j.ghir. 2005.07.001)

Draznin B 2006 Molecular mechanisms of insulin resistance: serine phosphorylation of insulin receptor substrate-1 and increased expression of p85alpha: the two sides of a coin. Diabetes $\mathbf{5 5}$ 2392-2397. (doi:10.2337/db06-0391)

Garvey WT, Hardin D, Juhaszova M \& Dominguez JH 1993 Effects of diabetes on myocardial glucose transport system in rats: implications for diabetic cardiomyopathy. American Journal of Physiology 264 H837-H844.

Giani JF, Bonkowski MS, Muñoz MC, Masternak MM, Turyn D, Bartke A \& Dominici FP 2008 Insulin signaling cascade in the hearts of long-lived growth hormone receptor knockout mice: effects of calorie restriction. Journals of Gerontology. Series A, Biological Sciences and Medical Sciences 63 788-797.

Gual P, Grémeaux T, Gonzalez T, Le Marchand-Brustel Y \& Tanti JF 2003 MAP kinases and mTOR mediate insulin-induced phosphorylation of insulin receptor substrate-1 on serine residues 307 , 612 and 632. Diabetologia 46 1532-1542. (doi:10.1007/s00125-0031223-4)

Izzard AS, Emerson M, Prehar S, Neyses L, Trainer P, List EO, Kopchick JJ \& Heagerty AM 2009 The cardiovascular phenotype of a mouse model of acromegaly. Growth Hormone $\mathcal{E} \mathcal{O}$ IGF Research 19 413-419. (doi:10.1016/j.ghir.2008.12.006)

Katz EB, Stenbit AE, Hatton K, DePinho R \& Charron MJ 1995 Cardiac and adipose tissue abnormalities but not diabetes in mice deficient in GLUT4. Nature 377 151-155. (doi:10.1038/377151a0)

Kopchick JJ, Bellush LL \& Coschigano KT 1999 Transgenic models of growth hormone action. Annual Review of Nutrition 19 437-461. (doi:10.1146/annurev.nutr.19.1.437)

Liu JL, Coschigano KT, Robertson K, Lipsett M, Guo Y, Kopchick JJ, Kumar U \& Liu YL 2004 Disruption of growth hormone receptor gene causes diminished pancreatic islet size and increased insulin sensitivity in mice. American Journal of Physiology. Endocrinology and Metabolism 287 E405-E413. (doi:10.1152/ajpendo.00423.2003)

Matthews DR, Hosker JP, Rudenski AS, Naylor BA, Treacher DF \& Turner RC 1985 Homeostasis model assessment: insulin resistance and beta cell function from fasting plasma glucose and insulin concentrations in man. Diabetologia 28 412-419. (doi:10.1007/ BF00280883)

McGrane MM, Yun JS, Moorman AF, Lamers WH, Hendrick GK, Arafah BM, Park EA, Wagner TE \& Hanson RW 1990 Metabolic effects of developmental, tissue-, and cell-specific expression of a chimeric phosphoenolpyruvate carboxykinase (GTP)/bovine growth hormone gene in transgenic mice. Journal of Biological Chemistry 265 22371-22379.

Møller N \& Jørgensen JO 2009 Effects of growth hormone on glucose, lipid, and protein metabolism in human subjects. Endocrine Reviews 30 152-177. (doi:10.1210/er.2008-0027)

Muniyappa R, Montagnani M, Koh KK \& Quon MJ 2007 Cardiovascular actions of insulin. Endocrine Reviews 28 463-491. (doi:10. 1210/er.2007-0006)

Muslin AJ 2008 MAPK signalling in cardiovascular health and disease: molecular mechanisms and therapeutic targets. Clinical Science $\mathbf{1 1 5}$ 203-218. (doi:10.1042/CS20070430)
Patterson B, Fields AV \& Shannon RP 2009 New insights into myocardial glucose metabolism: surviving under stress. Current Opinion in Clinical Nutrition and Metabolic Care 12 424-430. (doi:10.1097/MCO.0b013e32832c4167)

Proud CG 2004 Ras, PI3-kinase and mTOR signaling in cardiac hypertrophy. Cardiovascular Research 63 403-413. (doi:10.1016/ j.cardiores.2004.02.003)

Rizza RA, Mandarino LJ, Genest J, Baker BA \& Gerich JE 1985 Production of insulin resistance by hyperinsulinemia in man. Diabetologia 28 70-75.

Saccà L, Napoli R \& Cittadini A 2003 Growth hormone, acromegaly, and heart failure: an intricate triangulation. Clinical Endocrinology $\mathbf{5 9}$ 660-671. (doi:10.1046/j.1365-2265.2003.01780.x)

Slieker LJ, Sundell KL, Heath WF, Osborne HE, Bue J, Manetta J \& Sportsman JR 1992 Glucose transporter levels in tissues of spontaneously diabetic Zucker fa/fa rat (ZDF/drt) and viable yellow mouse (Avy/a). Diabetes 41 187-193. (doi:10.2337/diabetes. 41.2.187)

Ueno M, Carvalheira JB, Tambascia RC, Bezerra RM, Amaral ME, Carneiro EM, Folli F, Franchini KG \& Saad MJ 2005 Regulation of insulin signalling by hyperinsulinaemia: role of IRS-1/2 serine phosphorylation and the mTOR/p70 S6K pathway. Diabetologia 48 506-518. (doi:10.1007/s00125-004-1662-6)

Valera A, Rodriguez-Gil JE, Yun JS, McGrane MM, Hanson RW \& Bosch F 1993 Glucose metabolism in transgenic mice containing a chimeric P-enolpyruvate carboxykinase/bovine growth hormone gene. FASEB Journal 7 791-800.

Vieira VJ, Valentine RJ, Wilund KR, Antao N, Baynard T \& Woods JA 2009 Effects of exercise and low-fat diet on adipose tissue inflammation and metabolic complications in obese mice. American Journal of Physiology. Endocrinology and Metabolism 296 E1164-E1171. (doi:10.1152/ajpendo.00054.2009)

Volterrani M, Manelli F, Cicoira M, Lorusso R \& Giustina A 2000 Role of growth hormone in chronic heart failure. Therapeutic implications. Drugs60 711-719. (doi:10.2165/00003495-200060040-00002)

Wang Y 2007 Mitogen-activated protein kinases in heart development and diseases. Circulation 116 1413-1423. (doi:10.1161/CIRCULATIONAHA.106.679589)

Xu J \& Messina JL 2009 Crosstalk between growth hormone and insulin signaling. Vitamins and Hormones 80 125-153. (doi:10.1016/ S0083-6729(08)00606-7)

Yu W, Chen C, Fu Y, Wang X \& Wang W 2010 Insulin signaling: a possible pathogenesis of cardiac hypertrophy. Cardiovascular Therapeutics 28 101-105. (doi:10.1111/j.1755-5922.2009.00120.x)

Yue TL, Bao W, Gu JL, Cui J, Tao L, Ma XL, Ohlstein EH \& Jucker BM 2005 Rosiglitazone treatment in Zucker diabetic fatty rats is associated with ameliorated cardiac insulin resistance and protection from ischemia/reperfusion-induced myocardial injury. Diabetes 54 554-562. (doi:10.2337/diabetes.54.2.554)

Zhou Y, Xu BC, Maheshwari HG, He L, Reed M, Lozykowski M, Okada S, Cataldo L, Coschigamo K, Wagner TE et al. 1997 A mammalian model for Laron syndrome produced by targeted disruption of the mouse growth hormone receptor/binding protein gene (the Laron mouse). PNAS 94 13215-13220. (doi:10.1073/pnas.94.24.13215)

Zisman A, Peroni OD, Abel ED, Michael MD, Mauvais-Jarvis F, Lowell BB, Wojtaszewski JF, Hirshman MF, Virkamaki A, Goodyear LJ et al. 2000 Targeted disruption of the glucose transporter 4 selectively in muscle causes insulin resistance and glucose intolerance. Nature Medicine 6 924-928. (doi:10.1038/78693)

Received in final form 27 June 2011

Accepted 4 July 2011

Made available online as an Accepted Preprint 4 July 2011 